\title{
Physical Array Design
}

National Cancer Institute

\section{Source}

National Cancer Institute. Physical Array Design. NCI Thesaurus. Code C44180.

A design that is expected to be used to manufacture physical arrays. 